\title{
25 anos da Revista Brasileira de Atividade Física e Saúde
}

\section{5 years of the Brazilian Journal of Physical Activity and Health}

AUTOR
Markus Vinícius Nahas ${ }^{1}$ (D)
1 Professor aposentado da Universidade Federal de
Santa Catarina, Centro de Desporto, Florianópolis,
Santa Catarina, Brasil.
CONTATO
markusnabas@gmail.com
DOI

$10.12820 /$ rbafs. $26 \mathrm{e} 0200$

\section{(cc) BY}

Este trabalho está licenciado com uma Licença Creative Commons - Atribuição 4.0 Internacional.
Até o início dos anos 90, a Educação Física Brasileira não tinha como destaque a área de Atividade Física Relacionada à Saúde. A educação física escolar, o treino esportivo e o fitness das academias de ginástica eram as áreas acadêmicas e de atuação profissional que predominavam. Iniciativas pontuais nos anos 80 haviam inserido o tema aptidão física relacionada à saúde nas discussões e publicações da área ${ }^{1,2}$ - foi o início de um processo evolutivo inédito para a Educação Física brasileira.

Evidências de estudos epidemiológicos levaram, então, à mudança do foco no produto (aptidão física) para o processo (atividade física) na relação com saúde, mortalidade e expectativa de vida. No Brasil, a resposta da comunidade acadêmica foi rápida, acompanhando essas tendências dos grandes centros de pesquisa em atividade física e saúde, com a criação de grupos de pesquisa e áreas de formação na pós-graduação, a realização de eventos e publicações focadas nesta área específica (teses e dissertações, livros, revistas especializadas e anais de congressos).

Assim, iniciativas como as citadas e o subsequente envolvimento da Educação Física com a área de Saúde Pública, inicialmente nos programas de pós-graduação, fizeram com que o interesse acadêmico e a produção de pesquisas em atividade física e saúde aumentassem significativamente desde a última década do século passado. A epidemiologia da atividade física passou a ser uma realidade. Com núcleos de pesquisa consolidados e uma demanda crescente por espaços de divulgação das pesquisas, viu-se como natural a criação do Congresso Brasileiro de Atividade Física e Saúde (1997) e, uma década depois, da Sociedade Brasileira de Atividade Física e Saúde (2007).

Em 1995, por iniciativa pioneira de um grupo de profissionais de educação física da APEF de Londrina (PR), foi publicado o primeiro número daquele que viria a ser o periódico oficial da Sociedade Brasileira de Atividade Física \& Saúde. Atualmente, a Revista Brasileira de Atividade Física e Saúde (RBAFS) é um periódico científico de "acesso aberto e fluxo contínuo, de caráter multidisciplinar, com fins de disseminação de conteúdo cientifico de caráter teórico, empirico e educacional que contribui para o avanço da área de atividade física e saúde" (www.rbafs.org.br).

O esforço inicial dos professores Abdallah Achour Júnior e Dartagnan Pinto Guedes, com o respaldo da diretoria da APEF - Londrina, mostrou-se importante para o surgimento e posterior consolidação deste que viria a ser o principal veículo nacional de divulgação de artigos originais e de revisão, posicionamentos oficiais, editoriais e manifestações diversas da comunidade acadêmica em atividade física e saúde.

As linhas editoriais da RBAFS foram progressivamente ampliadas, 
acompanhando as tendências internacionais de investigação, incluindo atualmente abordagens dos níveis e determinantes da atividade física, comportamento sedentário e da aptidão física relacionados à saúde; desenvolvimento e validação de instrumentos de medidas; a interrelação atividade física, comportamento sedentário e aptidão física com saúde; intervenções para promoção da atividade física e formação de recursos humanos, abordagens históricas e socioculturais em atividade física. Tudo isso com uma política de acesso livre, "seguindo o principio de que disponibilizar gratuitamente o conhecimento cientifico ao público proporciona maior democratização do conhecimento" (www.rbafs.org.br).

Nestes 25 anos de existência e evolução constante, a RBAFS contou com grupos de pesquisadores que administraram, revisaram e publicaram, com grande empenho pessoal, o que de melhor se produziu em atividade física e saúde no Brasil e com significativas participações de autores renomados do exterior, desde o seu número 1, em 1995. Quando passou a ser o periódico oficial da SBAFS, o esforço de um grupo maior levou à consolidação da Revista que, atualmente aceita e publica trabalhos em três idiomas.

Tive o privilégio de participar diretamente e, mais recentemente, de acompanhar, essa conjunção da Revista Brasileira de Atividade Física e Saúde (1995), do Congresso Brasileiro de Atividade Física e saúde (1997) e da Sociedade Brasileira de Atividade Física e Saúde (2007), entidades que deram sustentabilidade, foco e qualificação aos frutos da comunidade acadêmica da área.

Aos 25 anos, a RBAFS está consolidada e tem mantido a periodicidade e a qualidade editorial de um grande periódico científico. Isso, graças ao esforço permanente de número de jovens pesquisadores que dedicam uma significativa parte de seu tempo e conhecimento ao gerenciamento, revisão de artigos e editoração da revista digital. Parabéns e meu respeito a todos que ajudaram a construir a RBAFS em tempos difíceis e àqueles que a aperfeiçoaram, acrescentando credibilidade e respeito perante a comunidade científica internacional.

\section{Referências}

1. Barbanti VJ. Aptidão Física Relacionada à saúde - Manual de testes. Brasilia: SEED - MEC, 1983. v. 1.32p.

2. Nahas MV. Knowledge and Attitudes of Low-Fit College Students Following a Short-Term Health Fitness Course [Tese de Doutorado]. University of Southern California; 1985. 